\title{
Effect of Project Complexity on Elemental Cost Analysis Accuracy: A Case of Residential Construction Projects within Nairobi City County
}

Muthoga, M. W.

BA ISAGO University

\begin{abstract}
The construction industry, in common with all industries, continually strives for progression and development. In view of the growing complexity in architectural designs, Quantity Surveyors have over years formulated and employed different cost estimating methods with a view to increase both accuracy and efficiency. However, very often these techniques are inaccurate and unstructured and are solely based on Quantity Surveyors' own experiences and general purpose procedures. It remains unexplored in both international and Kenyan literature how the growing diversity in project complexity affects elemental cost analysis accuracy. Against this backdrop, the present study sought to determine the effect of project complexity on elemental cost analysis accuracy with reference to residential projects within Nairobi City County. More specifically, the study sought to determine the effect of site conditions, project size, level of technology on elemental cost analysis accuracy with reference to residential projects within Nairobi City County. This study took the descriptive research design. The study used primary data which was quantitative in nature, collected by use of structured questionnaires. Both descriptive and inferential statistics were employed in data analysis. Findings reveal that site conditions are a significant determinant of elemental cost analysis accuracy among residential projects within Nairobi City County. The study also deduces that project size is a significant determinant of elemental cost analysis accuracy among residential projects within Nairobi City County. The level of technology used is also a significant determinant of elemental cost analysis accuracy among residential projects within Nairobi City County.
\end{abstract}

Keywords: Site Conditions, Project Size, Level of Technology, Elemental Analysis Accuracy

\section{Introduction}

The construction industry, in common with all industries, continually strives for progression and development. As Baccarini (2016) and Gidado (2016) have shown, construction has seen spiraling demands for speedier and improved construction, generating far greater levels of complexity. The financial estimate for a project carried out by the quantity surveyor (QS) is a typical example. The quantity surveying profession is constantly scrutinized, with regular demands for greater accuracy (Jaggar et al., 2014; Skitmore \& Marston, 2018). The question is whether this can be achieved when the complexity of construction projects is constantly growing.

According to Law (2014), in view of the growing complexity in architectural designs, QSs have over years, formulated and employed different cost estimating methods with a view to increase both accuracy and efficiency. However, very often these techniques are inaccurate and unstructured and are solely based on QSs' own experiences and general purpose procedures (Hegazy and Moselhi, 2015). Further, Carr (2015) has found a serious lack of commonly accepted estimating guidelines, despite the literature on the process and principles involved in costing. However, according to Berahim (2016), a structured and increasingly preferred cost estimating method is Elemental Cost Analysis (ECA).

Berahim (2016) defines ECA as a full appraisal of costs involved in previously constructed buildings and is aimed mainly at providing reliable information that will assist in accurately estimating cost of future buildings. It provides a product-based cost model, providing data on which initial elemental estimates and elemental cost plans can be based. The cost modeling that is ECA could be explained as the 
symbolic representation of a system, by articulating the contents of that system especially on the factors which influences its cost (Ferry, 2018; Jaggar et al., 2014; Skitmore and Marston, 2018). In this case, it serves the purpose to give confidence and economic assurance pertaining to the predicted project cost to the client (Ferry, 2018). Literature however lacks on ECA's application in projects with varying complexity hence the present study.

A cross-section of studies (Jaggar et al., 2014; Ferry, 2018; Skitmore \& Marston, 2018) however suggests that ECA should be referred together with other relevant documentations including the project priced BoQ, drawings, outline plans and elevations, showing plans and elevations and a list of elements whenever a cost estimating exercise is being carried out. Further, according to Ferry et al. (2018), in order to adapt the floor area rate from one project to another when shape is not known requires consideration of seven factors such as market conditions; size and number of storeys; specification levels; inclusions and exclusions; services; site and foundation conditions; and other relevant factors as well.

Mohr (2016) considered that complex projects involved tasks not well understood. Simon (2015) states that the complexity or simplicity of a structure depends critically upon the way it is described. It however remains unexplored in both international and Kenyan literature how diversity in project complexity affects ECA accuracy. Against this backdrop, the present study sought to determine the effect of project complexity on elemental cost analysis accuracy with reference to residential projects within Nairobi City County. More specifically, the study sought to determine the effect of Site Conditions, Project Size, Level of Technology on elemental cost analysis accuracy with reference to residential projects within Nairobi City County.

\section{Literature Review}

Klir (2017) used systems theory to evaluate complexity by considering its subjectivity. Complexity, he discovered, can be caused by complex systems and complex people. Similarly, systems are complex as a result of the number of parts and number of relationships between these parts (Barrow, 2016; Cilliers, 2016; Flood and Carson, 2017). Rijn (2017) believed that the best way was to compare similar projects and to identify comparable attributes. Melles et al. (2016) concluded that a measure of complexity creates a rather significant problem. They believed that this was due to complexity being a significant issue. A common mistake is to equate project cost with complexity, yet management teams are assigned on a percentage basis regardless of complexity levels.

Baccarini (2016) showed how complexity could be measured by way of differentiation and interdependency. Differentiation is defined as the difference in cognitive and emotional orientation amongst managers in different functional departments (Lawrence and Lorsch, 2013). Interdependency, is defined as being the degree of interrelatedness between these elements (Walker, 2016). These factors are clearly present in any construction project. Technological complexity, in terms of interactions, encompasses interdependencies between tasks, within a network of tasks, between different technologies and between inputs. In his study of complexity in the construction industry, Southwell (2017) commented that differentiation and interdependency are synonymous with the creation of complexity.

Walker (2016) and Hughes (2015) have shown that there are complex interdependencies in construction projects. They have also shown that differentiation in terms of skills or components (technology) is needed according to the complexity of the project's environment. Such diversity represents the amount of technological differentiation, and could be defined as the number of people of different trades or the number of 'work elements'. Such a measure would be well suited to the industry, which in terms of components is well suited to the methods of quantification.

The relationship between complexity and the size of a construction project is very important. Strong links have been proven between size and the level of differentiation (Pugh, 2018, Blau, 2015), yet the relationship between size and complexity is less clear. A number of studies have examined the issue, producing conflicting results. Child and Mansfield (2015) found a positive link between size and complexity, which was later challenged by Beyer and Trice (2016) and by Dewar and Hage (2016), who said that such a relationship was not provable. However, as size increases there is no real reason why different specialisms should be added except in terms of administration. Increasing the number of participants does not add to complexity in the same way as increasing the number of skills or technologies. Therefore, just because projects operate on a larger scale, it does not necessarily follow that they will be more complex. 
The results of previous studies looking into the accuracy of construction cost forecasts are contradictory and widely different (Smith 2015). For example, Flanagan and Norman (2015) examined 66 UK projects between 2006-08. Barely a quarter of projects had estimates within 5\% of the accepted tender. Bowen and Edwards (2017) discovered that the majority of QSs and architects expect a forecasting error of $\pm 5-6 \%$ from the pre-tender estimate. According to Ashworth (2018), accuracy is $\pm 13 \%$ on average, depending upon the size of the scheme, the method used and luck.

Skitmore (2016) claims that the accuracy of pre-tender estimates will be in the region of $\pm 8 \%$. Clients feel, quite naturally, aggrieved when they have to produce more finance than was originally planned. Raftery (2014) proposes that the new generation of cost models developed since the 1970s were produced mainly as a reaction to the dissatisfaction that existed with traditional forecasting methods. With accuracy in the region of $\pm 13 \%$ (Ashworth, 2018), are estimates really worth bothering with and why is it that these costs cannot be forecast at an earlier stage?

Morrison (2014) argued that there is a strong tendency to rely on historic costings in the pricing of similar structures. He however takes the view that the largest inaccuracies exist with imperfections in the cost data used and adjustments made to this data to allow for time, location and market conditions. Perhaps more importantly, the use of cost databases in principle may be wrong, based on the dubious premise that the building's total cost is equal to the sum of its constituent parts. This is simply not the case when issues such as buildability and complexity feature on the list of cost determinants. The technology used in construction processes is also

Constantly changing.

Ashworth et al. (2017) found that many estimators believed that their current methods gave good results, but few could offer hard evidence to support this belief. They concluded that the accuracy of construction estimators is much less satisfactory than most would claim and some estimators are more accurate than others. The reasoning for this lies with experience and judgement, which can only be developed over a period of time (Beeston 2015). Other less obvious factors are also significant, for example, market conditions. A failure on behalf of the QS to read the market conditions will undoubtedly result in poor forecasts (Flanagan and Norman 2015). Pressure is also sometimes brought to bear on the QS to produce a figure acceptable to the client. Such diplomatic cost techniques are, however, very risky and, ultimately, flawed. General external factors influencing the accuracy of an estimate include the level of risk and uncertainty in the project, regional variations, market forces and collusive tendering.

Laptali et al. (2017) stated that whenever the construction projects are meant to be profit making, the best estimate figure is therefore very essential for the contractor to be awarded the construction contract, and hence, the quantity surveyors or estimators should be able to determine the whole project cost even though it is a total subcontracted works. These prices are including especially for activities of groundwork, brickwork, joints, carpentry, concrete; formwork and reinforcement. As a consequence, computer software can be utilized to increase the speed of estimating the repetitive calculations for similar or common items in the projects.

\section{Research Methodology}

This study took the descriptive research design. According to Kombo and Tromp (2016), the basic purpose for descriptive research usually is to describe characteristics of the population of interest, make specific predictions and test associational relationships. The target population for the study was the 672 companies on the Nairobi City County database registered as Quantity Surveyors. To arrive at a desired sample size, the study employed the Yamane (2018) formula as follows:

Where;

$$
\mathrm{n}=\overline{1+(\mathrm{N}} * \overline{\mathrm{N}} \overline{\left.\mathrm{e}^{2}\right)}
$$

$\mathrm{N}=$ population size

$\mathrm{e}=$ Tolerance at desired level of confidence, take 0.05 at $95 \%$ confidence level $\mathrm{n}=$ sample size . 
How the formula is used is shown below

$\mathrm{n}=672 /(1+(672 * 0.05 * 0.05))$

$\mathrm{n}=250.75$

The established sample size was therefore 250, who were randomly sampled within Nairobi City County.

The study used primary data which was quantitative in nature, collected by use of structured questionnaires. Gall et al., (2016) points out that, questionnaires are appropriate for studies since they collect information that is not directly observable as they inquire about feelings, motivations, attitudes, accomplishments as well as experiences of individuals. The data collected was analyzed by both descriptive and inferential statistics. Descriptive statistics entailed the use of frequencies in their absolute and relative forms (percentage). Mean and standard deviations were also used as measures of central tendencies and dispersion respectively. Inferential statistics on the other hand involved both Pearson correlation and regression analysis, employing the following model:

$Y=\beta_{0}+\beta_{1} X_{1}+\beta_{2} X_{2}+\beta_{3} X_{3}+\beta_{4} X_{4}+\varepsilon$

Where:

$Y=$ Elemental Cost Analysis accuracy
$\beta_{0}=$ Constant Term;
$\beta_{1}-\beta_{4}=$ Beta coefficients;
$X_{1}=$ Site Condition;
$X_{2}=$ Project Size;
$X_{3}=$ Level of Technology;
$\varepsilon=$ Error term

\section{Results}

The study achieved a response rate of $78.8 \%$ with 197 respondents reached, out of the 250 targeted. According to Mugenda and Mugenda (2003), a response rate of 50\% is adequate for analysis and reporting; a rate of $60 \%$ is good and a response rate of $70 \%$ and over is excellent. The study therefore attained an excellent response rate as presented in Table 4.1.

\subsection{Effect of Project Site Condition on ECA Accuracy}

The study sought to determine the effect of Project Site Condition on ECA accuracy with reference to residential projects within Nairobi City County. To this end, respondents were asked to indicate the respective extent at which various site condition elements determine ECA accuracy. This was on a five-point Likert scale, where, $1=$ Not at all; $2=$ A Small Extent; 3 = Moderate Extent; 4 = Great Extent; $5=$ Very Great Extent. The scales of Not at all and A Small Extent have been taken to represent minimal effect, equivalent to mean score of 0 to 2.5. The score of 'Moderate Extent' has been taken to represent moderate effect, equivalent to a mean score of 2.6 to 3.4. The score of 'Great Extent' and 'Very Great Extent' have been taken to represent great effect, equivalent to a mean score of 3.5 to 5.4. Table 4.2 presents the findings.

As presented in Table 4.2, a majority of respondents affirmed that ground conditions (4.41), topography (4.09) and soil conditions (4.03) respectively have the greatest effects on ECA accuracy with reference to residential projects within Nairobi City County. Respondents further affirmed that Conflicting utilities including buried pipe, cables and overhead lines among others also affect ECA accuracy to a great extent. Respondents however indicated that site position (3.43), weather problems (3.41) and site access (3.19) determine ECA accuracy to a moderate extent.

\subsection{Effect of Project Size on ECA Accuracy}

The study sought to determine the effect of Project size on ECA accuracy with reference to residential projects within Nairobi City County. To this end, respondents were asked to indicate the respective extent at which various project size elements determine ECA accuracy. This was on a five-point Likert scale, where, 1= Not at all; 2 = A Small Extent; 3 = Moderate Extent; 4 = Great Extent; 5 = Very Great Extent. The scales of Not at all and A Small Extent have been taken to represent minimal effect, equivalent to mean score of 0 to 2.5. The score of 'Moderate Extent' has been taken to represent moderate effect, equivalent to a mean 
score of 2.6 to 3.4. The score of 'Great Extent' and 'Very Great Extent' have been taken to represent great effect, equivalent to a mean score of 3.5 to 5.4. Table 4.3 presents the findings.

Table 4.3 Extent of Project Size Effects on ECA Accuracy

\begin{tabular}{|l|l|l|}
\hline Statement & Mean & Std. Dev \\
\hline Scale of construction & 4.38 & 0.505 \\
\hline Project budget & 4.01 & 0.307 \\
\hline Number of project team & 3.12 & 0.374 \\
\hline Amount of special work & 4.29 & 0.620 \\
\hline Number of skills required & 3.47 & 0.636 \\
\hline
\end{tabular}

A majority of respondents affirmed that the scale of construction (4.38), amount of special work (4.29) and project budget (4.01). Number of skills required (3.47) and number of project team (3.12) were however, found to determine accuracy with reference to residential projects within Nairobi City County to a moderate extent.

\subsection{Effect of Level of Technology on ECA Accuracy}

The study sought to determine the effect of level of technology on ECA accuracy with reference to residential projects within Nairobi City County. To this end, respondents were asked to indicate the respective extent at which various level of technology elements determine ECA accuracy. This was on a five-point Likert scale, where, $1=$ Not at all; $2=$ A Small Extent; $3=$ Moderate Extent; $4=$ Great Extent; $5=$ Very Great Extent. The scales of Not at all and A Small Extent have been taken to represent minimal effect, equivalent to mean score of 0 to 2.5. The score of 'Moderate Extent' has been taken to represent moderate effect, equivalent to a mean score of 2.6 to 3.4. The score of 'Great Extent' and 'Very Great Extent' have been taken to represent great effect, equivalent to a mean score of 3.5 to 5.4. Table 4.4 presents the findings.

Table 4.4 Extent of Level of Technology Effects on ECA Accuracy

\begin{tabular}{|l|l|l|}
\hline Statement & Mean & Std. Dev \\
\hline Types of innovation in construction materials (eg. Concrete blocks, roof, pillars) & 3.725 & .1092 \\
\hline Types of technological equipment and tools used & 3.857 & .3648 \\
\hline Use of computerized systems in designing & 4.481 & .5931 \\
\hline Use of building information modelling & 4.571 & .2103 \\
\hline
\end{tabular}

A majority of respondents were found to affirm that use of building information modelling (4.571); use of computerized systems in designing (4.481); types of technological equipment and tools used (3.857); and types of innovation in construction materials, for example concrete blocks, roof and pillars (3.725).

\subsection{ECA Accuracy}

The study sought to assess the level of ECA accuracy among respondent QS firms in their residential projects within Nairobi City County. To this end, respondents asked to indicate levels of agreement with respective levels of cost variation $(\mathrm{CV})$. This was also on a five-point Likert scale, where, $1=$ strongly disagree; $2=$ disagree; $3=$ neutral; $4=$ agree; $5=$ strongly agree. The scores of 'Strongly Disagree' and 'Disagree' have been taken to represent a statement disagreed with by a majority of respondents, equivalent to mean score of 0 to 2.5. The score of 'Neutral' has been taken to represent a statement affirmed to moderately, equivalent to a mean score of 2.6 to 3.4. The score of 'Agree' and 'Strongly Agree' have been taken to represent a statement highly agreed with by a majority of respondents, equivalent to a mean score of 3.5 to 5.4. Table 4.5 presents the findings. 
Table 4.5 ECA Accuracy

\begin{tabular}{|l|l|l|}
\hline Statement & Mean & Std. Dev \\
\hline $\mathrm{CV} \leq 5 \%$ & 3.748 & 0.0429 \\
\hline $5 \%<\mathrm{CV} \leq 10 \%$ & 3.984 & 0.8592 \\
\hline $10 \%<\mathrm{CV} \leq 20 \%$ & 3.419 & 0.3056 \\
\hline $\mathrm{CV}>20 \%$ & 3.387 & 1.3078 \\
\hline
\end{tabular}

As presented in the table, a majority of respondents affirmed to recording cost variations of between $5 \%$ and $10 \%$ (3.984) followed by cost variations of less than 5\%. A majority of respondents only moderately affirmed to between $10 \%$ and $20 \%$; and over $20 \%$ cost variations only to a moderate extent.

\subsection{Inferential Statistics}

To establish the degree of influence of the independent and dependent variables, regression analysis was conducted among the variables, with the assumption that: variables are normally distributed to avoid distortion of associations and significance tests, which was achieved as outliers were not identified; a linear relationship between the independent and dependent variables for accuracy of estimation, which was achieved as the standardized coefficients were used in interpretation. The regression analysis produced the Model Goodness of Fit, Analysis of Variance (ANOVA) and coefficients of determination as presented in Table 4.6 below.

Table 4.6 Regression Analysis

Model Summary

\begin{tabular}{|l|r|r|r|r|}
\hline Model & R & R Square & Adjusted R Square & \multicolumn{1}{c|}{$\begin{array}{c}\text { Std. Error of the } \\
\text { Estimate }\end{array}$} \\
\hline 1 & $.642^{\mathrm{a}}$ & .413 & .404 & .21233 \\
\hline
\end{tabular}

a. Predictors: (Constant), Site conditions, Project size, Level of technology

ANOVA ${ }^{a}$

\begin{tabular}{|ll|r|r|r|r|r|}
\hline Model & & Sum of Squares & df & Mean Square & F & Sig. \\
\hline 1 & Regression & 6.115 & 3 & 2.038 & 45.212 & $.000^{\mathrm{b}}$ \\
& Residual & 8.701 & 193 & .045 & & \\
& Total & 14.816 & 196 & & & \\
\hline
\end{tabular}

a. Dependent Variable: ECA Accuracy

b. Predictors: (Constant), Site conditions, Project size, Level of technology

Coefficients $^{a}$

\begin{tabular}{|c|c|c|c|c|c|c|}
\hline \multirow{2}{*}{\multicolumn{2}{|c|}{ Model }} & \multicolumn{2}{|c|}{ Unstandardized Coefficients } & $\begin{array}{l}\text { Standardized } \\
\text { Coefficients }\end{array}$ & \multirow[b]{2}{*}{$\mathbf{t}$} & \multirow[b]{2}{*}{ Sig. } \\
\hline & & $\mathrm{B}$ & Std. Error & Beta & & \\
\hline \multirow[t]{4}{*}{1} & (Constant) & 1.096 & .187 & & 5.852 & .000 \\
\hline & $\begin{array}{l}\text { Level of } \\
\text { technology }\end{array}$ & .033 & .008 & .269 & 4.220 & .000 \\
\hline & Project size & .031 & .004 & .447 & 7.773 & .000 \\
\hline & Site conditions & .013 & .006 & .139 & 2.245 & .026 \\
\hline
\end{tabular}

a. Dependent Variable: ECA Accuracy

As presented in table 4.6, the model goodness of fit showed a correlation value (R) of 0.642 which depicts that there is a good linear dependence between the independent and dependent variables. With an adjusted R-squared of 0.404, the model shows that site conditions, project size and level of technology explain 40.4 percent of the variations in ECA accuracy while 59.6 percent is explained by other factors not included in the model. 
Regression analyses produced the coefficients of determination and Analysis of Variance (ANOVA). Analysis of variance was done to show whether there is a significant mean difference between dependent and independent variables. The ANOVA was conducted at 95\% confidence level. As presented in Table 4.6, ANOVA statistics was conducted to determine the differences in the means of the dependent and independent variables to show whether a relationship exists between the two.

The P-value of .000 implies that ECA accuracy has a significant joint relationship with site conditions, project size and level of technology which is significant at 95\% confidence level. This implies that the regression model is significant and can thus be used to assess the association between the dependent and independent variables. The data in table 4.6 further reveals a positive relationship between ECA accuracy and all the independent variables.

Taking the regression model: $Y=\alpha+\beta_{1} X_{1}+\beta_{2} X_{2}+\beta_{3} X_{3}+\epsilon$, the established regression equation was:

$\mathrm{ECA}$ accuracy $=1.096+.033($ Level of technology $)+.031$ (Project size $)+.013$ (Site conditions $)+.187$

The findings are of the implication that a unit change in Level of technology would lead to a .033 change in ECA accuracy keeping all other factors constant; a unit change in Project size would lead to a .031 change in ECA accuracy keeping all other factors constant and a unit change in Site conditions would lead to a .013 change in ECA accuracy keeping all other factors constant.

\section{Conclusions}

The foregoing findings are of the implication that site conditions are a significant determinant of ECA accuracy among residential projects within Nairobi City County. Among the key site condition factors include ground conditions, topography, soil conditions, and conflicting utilities including buried pipe, cables and overhead lines among others also affect ECA accuracy to a great extent.

The study also deduces that project size is a significant determinant of ECA accuracy among residential projects within Nairobi City County. Among the key site condition, factors that affect ECA accuracy to a great extent include the scale of construction, amount of special work and project budget. Number of skills required and number of project team however only determine ECA accuracy to a moderate extent.

The level of technology used is also a significant determinant of ECA accuracy among residential projects within Nairobi City County. Among the key site condition factors that affect ECA accuracy to a great extent include use of building information modelling; use of computerized systems in designing; types of technological equipment and tools used; and types of innovation in construction materials, for example concrete blocks, roof and pillars.

\section{References}

[1.] Ashworth, A. (2018). Cost studies of buildings. 3ed. Harlow: Longman Scientific and Technical.

[2.] Ashworth, A. G. (2017). An analysis of the accuracy of some builders estimating. Quantity Surveyor. 36, April, 65-70.

[3.] Baccarini, D. (2016). The concept of project complexity: a review. International Journal of Project Management, 14(4): 201-204.

[4.] Barrow, J. (2016). Impossibility: The limits of science and the science of limits. Oxford: Oxford University Press.

[5.] Beeston, D.T. (2015). Statistical methods for building price data. London: Spon

[6.] Berahim, I. K. (2016). Development of Database Management System (DBMS) Based on Elemental Cost Analysis (ECA) Methodology. Masters thesis, Universiti Teknologi Malaysia.

[7.] Beyer, J.M. \& Trice, H.M. (2016). A re-examination of the relations between size and various components of organisational complexity. Administrative Science Quarterly. 24: 48-64.

[8.] Blau, P.M. (2015). Interdependence and hierarchy in organisatons. Social Science Research. 1, 1 24.

[9.] Bowen, P.A. \& Edwards, P.J. (2017). Cost modelling and price forecasting: practice and theory in perspective. Construction Management and Economics. 3(3): 199-215

[10.] Carr R. I. (2015). Cost Estimating Principles. Journal of Construction Engineering and Management. 115(4), 545-551. 
[11.] Child, J. \& Mansfield, R. (2015). Technology, size and organization structure. Sociology. 6: 369393.

[12.] Baccarini, D (2016). The concept of project complexity: a review. International Journal of Project Management, 14(4): 201-204.

[13.] Cilliers, P. (2016). Complexity and post-modernism. London: Routledge.

[14.] Dewar, R. \& Hage, J. (2016). Size, technology, complexity and structural differentiation: towards a theoretical synthesis.

[15.] Ferry D. J. (2018). Cost Planning of Buildings. Seventh Edition. Great Britain: Blackwell Publishing.

[16.] Flanagan, R. \& Norman, G. (2015). Accuracy and monitoring of quantity surveyors' price forecasting for building work. Construction Management and Economics. 1(2): 157-180.

[17.] Flanagan, R. \& Norman, G. (2015). Accuracy and monitoring of quantity surveyors' price forecasting for building work. Construction Management and Economics. 1(2): 157- 180.

[18.] Flood, R.L. \& Carson, E.R. (2017). Dealing with complexity: an introduction to the theory and application of systems science. New York: Plenum Press.

[19.] Gidado, K.I (2016). Project complexity: the focal point of construction production planning. Construction Management and Economics. 14(4): 213-225.

[20.] Hegazy T. and Moselhi O. (2015). Elements of Cost Estimation: A Survey in Canada and the United States. Cost Engineering. 37(5), 27-31.

[21.] Hughes, W.P. (2015). Organisational analysis of building projects. Unpublished Ph.D. thesis. Department of Surveying, Liverpool Polytechnic

[22.] Jaggar D., Ross A., Smith J. and Love P. (2014). Building Design Cost Management. Osney Mead, Oxford, UK: Blackwell Science Ltd.

[23.] Klir, G.J. (2017) Complexity: some general observations. Systems Research. 2(2): 141-163

[24.] Laptali E., Bouchlaghem N. and Wild S. (2017). Planning and Estimating in Practice and the Use of Integrated Computer Models. Automation in Construction 7. 71-76.

[25.] Law C. (2014). Building Contractor Estimating: British Style. Cost Engineering. 36(6), 23-28.

[26.] Lawrence, P.R. \& Lorsch, J.W. (2013) Organisation and environment: managing differentiation and integration. Boston: Harvard Business School Press

[27.] Melles, B., Roberts, J.C.B. \& Wamelink, J.W.F. (2016). A typology for the selection of management techniques in the construction industry. In: Skitmore, R.M. (ed) Procs.

[28.] Mohr, L.B (2016). Organisational technology and organisational structure. Administrative Science Quarterly. 16: 444-459.

[29.] Pugh, D. (2018). Dimensions of organisational structure. Administrative Science Quarterly, 13: 65105.

[30.] Raftery, J. (2014). Principles of building economics. Oxford: BSP Professional Morrison, N. (2014) Accuracy of quantity surveyors, cost estimating. Construction Management and Economics. 2(1): 57-75.

[31.] Rijn, T.J.M. (2017). Produceren Door Inforneren. Deventer: Kluwer.

[32.] Simon, H.A. (2015). The architecture of complexity. General Systems Yearbook. 10: 63-64.

[33.] Skitmore R. M. \& Marston V. K. (2018). Cost Modelling. London, Great Britain: E \& FN Spon, Taylor and Francis Group.

[34.] Skitmore, R.M. (2016). The accuracy of construction price forecasts: a study of QS performance in early stage estimating. Department of Surveying, Salford University

[35.] Smith, A.J. (2015). Estimating, tendering and bidding for construction. London: Macmillan

[36.] Southwell, M. (2017). Projects and the management of complexity. Unpublished M.Sc. Thesis. Department of Construction Management \& Engineering, University of Reading

[37.] Walker, A. (2016). Project Management in Construction. Oxford: Blackwell Science 